\title{
Evidence for Tonic Activation of NK-1 Receptors during the Second Phase of the Formalin Test in the Rat
}

\author{
J. L. Henry, ${ }^{1,2}$ K. Yashpal, ${ }^{2,4}$ G. M. Pitcher, ${ }^{1}$ J.-G. Chabot, ${ }^{2,6}$ and T. J. Coderre ${ }^{3,4,5}$ \\ ${ }^{1}$ Department of Physiology, McGill University, Montreal, Quebec, H3G 1 Y6 Canada, ${ }^{2}$ Department of Psychiatry, McGill \\ University, Montreal, Quebec, H3A 1 A1 Canada, ${ }^{3}$ Department of Psychology, McGill University, Montreal, Quebec, H3A \\ 1 1B1 Canada, ${ }^{4}$ Pain Mechanisms Laboratory, Clinical Research Institute of Montreal, Montreal, Quebec, H2W 1R7 \\ Canada, ${ }^{5}$ Département de Médecine, Université de Montréal, Montreal, Quebec, H3C 3J7 Canada, and ${ }^{6}$ Douglas \\ Hospital Research Centre, Verdun, Quebec, H4H 1R3 Canada
}

Behavioral, electrophysiological, and autoradiographic experiments were done to study the second nociceptive phase in the formalin test. In initial experiments, this second phase was attenuated by $1-10 \mathrm{mg}$ of the $\mathrm{NK}-1$ receptor antagonist CP99,994, given subcutaneously 10,30 , or 60 min before formalin ( $n=8-10$ ) and by $20 \mu \mathrm{g}$ given intrathecally 20 min after formalin ( $n=13$ ); the inactive isomer CP-100,263 was ineffective. In electrophysiological experiments on single dorsal horn neurons in vivo, the excitatory responses to subcutaneous formalin injection (50 $\mu \mathrm{l}, 2.5 \%$ ) were attenuated by subsequent intravenously administration of the NK-1 receptor antagonist CP96,345 ( $0.5 \mathrm{mg} / \mathrm{kg} ; n=8$ ), given 35-40 min after formalin, but not by the inactive enantiomer CP-96,344 $(0.5 \mathrm{mg} / \mathrm{kg} ; n=9)$. Finally, autoradiographic binding of exogenous $\left[{ }^{125} \mathrm{l}\right] \mathrm{BH}-$ substance $P$ in the lumbar cord was reduced at 5 and 25 min after formalin (50 $\mu \mathrm{l}, 1$ or $5 \%$ ), with an intermediate level of reduction at $12 \mathrm{~min}$. These data are interpreted as evidence that the second phase of nociceptive scores in the formalin test is attributable at least partially to tonic activation of $\mathrm{NK}-1$ receptors at the spinal level, whether because of a temporally limited release of substance $P$, for example only during the first phase, but a slow removal or breakdown of substance $\mathrm{P}$, or, more likely, because of tonic release from primary afferents throughout the second phase. Irrespective of the mechanism, it can be concluded that at least some of the persistent nociceptive effects associated with peripheral inflammation, or at least those provoked by subcutaneous injection of formalin, are mediated via continuous activation of NK-1 receptors at the level of the spinal dorsal horn; this may relate directly to mechanisms underlying prolonged nociceptive pains in humans.

Key words: substance $P$; substance $P$ receptor; NK-1 receptor; tachykinin; substance $P$ antagonist; CP-96,345; CP-99,994; nociception; formalin test; wide dynamic range neuron; dorsal horn; spinal cord; intrathecal; binding; autoradiography
The formalin test is commonly used as a model of acute and tonic pain, and sometimes even of inflammatory or chronic pain, or hyperalgesia. The nociceptive response to injection of dilute formalin into the plantar surface, usually of the hindpaw, consists of an early favoring, biting and licking of the injected paw, then a period of reduced nociceptive responses, and finally a second period of favoring and licking. More attention has been paid to mechanisms eliciting the second nociceptive phase, perhaps because some pharmacological manipulations that block the first phase tend also to block the second phase, and it has been argued that the second phase must be influenced by central changes induced during the first phase. Thus, the second nociceptive phase has been presented as a form of central sensitization. In view of evidence that lidocaine-induced block of the thoracic spinal cord fails to alter nociceptive responses in the formalin test (Coderre et al., 1994), it appears that at least some of the mechanisms giving rise to the second phase responses lie below

Received Feb. 3, 1999; revised April 16, 1999; accepted May 17, 1999.

This study was supported by grants from the Canadian Medical Research Council to J.L.H., T.J.C., and J.-G.C. G.M.P. was a student supported by the Royal Victoria Hospital Research Institute, McGill Faculty of Medicine, and the Fonds pour la formation de chercheurs et l'aide à la recherche (Province of Quebec). CP-96,345, CP-96,344, CP-99,994, and CP-100,263 were generously provided by Pfizer Central Research, Groton, CT.

Correspondence should be addressed to Dr. J. L. Henry, Department of Physiology, McGill University, 3655 Drummond Street, Montreal, Quebec, H3G 1Y6 Canada.

Copyright (C) 1999 Society for Neuroscience $\quad 0270-6474 / 99 / 196588-11 \$ 05.00 / 0$ the thoracic cord. This conclusion is strengthened by the further observation that in rats chronically spinalized at the midthoracic level, nociceptive responses to formalin could still be elicited (Coderre et al., 1994).

At the spinal level, various chemical messengers have been implicated in mediating or otherwise bringing about the second nociceptive phase, including substance P (Ohkubo et al., 1990), which we have been studying for some time. Consistent with a role for substance $\mathrm{P}$ in mediating these nociceptive responses, subcutaneous injection of formalin induces the release of substance $\mathrm{P}$ in the superficial dorsal horn (McCarson and Goldstein, 1991) and an increase in the number of spinal dorsal horn neurons expressing c-fos, and this increase is reduced by an NK-1 receptor antagonist (Chapman et al., 1996; Tao et al., 1997). In vivo, dorsal horn neurons show similar increases in excitability in response to formalin injection, but both the first and second excitatory phases have been reported to be inhibited by pretreatment with an NK-1 receptor antagonist (Chapman and Dickenson, 1993). Intrathecal administration of substance $\mathrm{P}$ increases the nociceptive scores during the second nociceptive phase (Ohkubo et al., 1990; Coderre and Yashpal, 1994; although see Mjellem-Joly et al., 1992; Sakurada et al., 1993a). This second phase is reduced by administration of a substance $\mathrm{P}$ (NK-1) receptor antagonist (Yamamoto and Yaksh, 1991; Yashpal et al., 1993). Importantly, the antagonism of the second phase response by NK-1 receptor antagonists has been reported to occur only when these antago- 
nists are administered before the formalin is injected (Yamamoto and Yaksh, 1991; Traub, 1996), prompting the suggestion that substance $\mathrm{P}$ is involved in the generation but not the maintenance of the hyperalgesia (Yamamoto and Yaksh, 1991; Traub, 1996).

Although this evidence ties substance $\mathrm{P}$ to processes in the spinal cord referred to generally as central sensitization, other evidence suggests a peripheral contribution to nociceptive responses in the second phase of the formalin test, raising the possibility of continuous release of substance $\mathrm{P}$ during this second phase. Nerve block of the first phase did not influence the second phase response (Dallel et al., 1995). Systemic (Abbadie et al., 1997) or hindpaw (Coderre et al., 1990) administration of a local anesthetic after formalin injection depresses the second phase response. Recordings from primary afferents indicate that injection of formalin into the receptive field produces a biphasic activation of $\mathrm{A}$ and $\mathrm{C}$ fibers with a time course parallel to the behavioral response to formalin injection (McCall et al., 1996; Puig and Sorkin, 1996). A conclusion from these studies is that the second phase cannot be entirely caused by central sensitization (Dallel et al., 1995).

Thus, to determine whether tonic activation of NK-1 receptors contributes to the second phase of the formalin test, an NK-1 receptor antagonist was given after the onset of the second phase in both behavioral and electrophysiological studies and by measuring the binding of exogenous substance $\mathrm{P}$ in the dorsal horn at different times after injection of formalin (Yashpal et al., 1994).

Some of the results have been presented in abstract form (Yashpal et al., 1996).

\section{MATERIALS AND METHODS}

In all cases, the guidelines described in The Care and Use of Experimental Animals of the Canadian Council of Animal Care, Vols. 1 and 2, were strictly followed. In addition, all animal protocols were examined and approved by the Animal Care Committees of McGill University and of the Clinical Research Institute of Montreal.

\section{Behavioral studies}

Male Sprague Dawley rats (300-400 gm) were used.

Formalin test. In this paradigm, each rat was given a subcutaneous injection of $50 \mu \mathrm{l}$ of $2.5 \%$ formalin into the plantar surface of one hindpaw using a 27 gauge syringe needle. Each rat was then immediately placed in a Plexiglas box $(30 \times 30 \times 30 \mathrm{~cm})$ positioned over a mirror angled at $45^{\circ}$ to allow an unobstructed view of the paws by the observer. Observations to determine nociceptive responses began after placing the rat into the box and continued for the next $60 \mathrm{~min}$. A nociceptive score was determined for each 5 min block during that period by measuring the amount of time spent in each of four behavioral categories: 0 , treatment of the injected hindpaw is indistinguishable from that of the contralateral paw; 1 , the injected paw has little or no weight placed on it; 2 , the injected paw is elevated and is not in contact with any surface; 3 , the injected paw is licked, bitten, or shaken. Then, a weighted nociceptive score, ranging from 0 to 3 was calculated by multiplying the time spent in each category by the category weight, summing these products, and dividing by the total time for each 5 min block of time.

Subcutaneous administration of CP-99,994 before formalin injection. Eight groups of rats were used to determine the optimal dose and the optimal time of administration of (+)-(2S,3S)-3-(2-methoxybenzylamino)2-phenylpiperidine (CP-99,994) in the formalin test. Information on the synthesis, properties, and bioavailability of this antagonist has been reported (McLean et al., 1993). CP-99,994 was injected subcutaneously in doses of 1,5 , and $10 \mathrm{mg} / \mathrm{kg}$ in a volume of $0.1 \mathrm{ml} / 100 \mathrm{gm}$ of body weight. In the first series of experiments, CP-99,994 was given subcutaneously $30 \mathrm{~min}$ before formalin injection. Control rats were given a subcutaneous injection of saline $(0.9 \% \mathrm{NaCl})$. Nociceptive scores were measured from the time of formalin injection for $50 \mathrm{~min}$.

In a second series, $5 \mathrm{mg} / \mathrm{kg}$ of CP-99,994 was given 10 or $60 \mathrm{~min}$ before formalin injection (as compared with $30 \mathrm{~min}$ in the previous experiment), and nociceptive scores were measured for $50 \mathrm{~min}$ following the formalin injection. Rats were otherwise treated the same as in the previous groups.

Intrathecal administration of CP-99,994 and CP-100,263 before formalin injection. CP-99-994 was administered intrathecally 20 min after formalin injection, with the rationale to determine whether the second phase could be blocked once the response had started. In this experiment each rat was implanted with a chronic indwelling intrathecal catheter (Intramedic PE-10) under chloral hydrate anesthesia $(300 \mathrm{mg} / \mathrm{kg}$, i.p.). This catheter was inserted through an incision in the dura at the atlantooccipital junction and was positioned so that the inner tip lay at the lower lumbar vertebral level. Spinous processes were used as landmarks for this positioning (Yashpal et al., 1985). The outer end of the catheter was fixed with dental cement to a screw embedded in the skull. The exact location of the inner tip of the catheter was verified routinely during postmortem examination. Results were included only if the tip of the catheter was confirmed to lie at the lumbar level. In addition, the viability of the intrathecal catheter was checked by injecting $20 \mu \mathrm{l}$ of lidocaine (a 1\% aqueous solution) the day before testing; implantation was considered to have been successful in rats showing motor and sensory loss within 2 min of administration of lidocaine and a reversal of these effects within 5-10 $\mathrm{min}$. The rats were allowed to recover for $4-6 \mathrm{~d}$ after implantation of the catheter, and only those animals that were free of any neurological deficit were used in the experiments. CP-99,994 or its inactive isomer CP100,263 was given intrathecally in a single dose of $20 \mu \mathrm{g}$ in $10 \mu \mathrm{l}$ of artificial CSF [an aqueous solution of (in mM) $128.6 \mathrm{NaCl}, 2.6 \mathrm{KCl}, 1.0$ $\mathrm{MgCl}_{2}$, and $1.4 \mathrm{CaCl}_{2}$, phosphate buffered to $\mathrm{pH}$ 7.33]. This was followed by an additional $10 \mu \mathrm{l}$ of CSF to flush the catheter (approximate internal volume was $8 \mu \mathrm{l}$ ). CSF replaced the drug solution in control rats.

Data analysis. Nociceptive scores over the $5 \mathrm{~min}$ time blocks were analyzed using repeated measures ANOVA, with comparisons between experimental groups and the control group at each time interval using Dunnett's post hoc $t$ test and between experimental groups using Newman-Keuls' post hoc test.

\section{Electrophysiological studies}

Experiments were done on adult, male Sprague Dawley rats from Charles River (St. Constant, Quebec, Canada).

Animal preparation. Male Sprague Dawley rats (350-375 gm) were anesthetized with sodium pentobarbital $(50 \mathrm{mg} / \mathrm{kg}$, i.v.; Abbott Laboratories, Montreal, Quebec, Canada). The right common carotid artery and jugular vein were catheterized for continuous monitoring of arterial pressure and for injection of drugs, respectively. Spinal cord segments $L_{1}$ to $\mathrm{L}_{3}$ were exposed for recording. The spinal cord was transected at the $\mathrm{T}_{9}$ vertebral level to eliminate supraspinal influences on the activity of lumbar dorsal horn neurons. Just before transection, lidocaine $(0.05 \mathrm{ml}$ of 1\%; Astra Pharma, Mississauga, Ontario, Canada) was injected into the spinal cord at the level of transection to minimize spinal shock. The rats normally breathed spontaneously, and if the breathing pattern became irregular or if respiratory arrest occurred, the animal was paralyzed with pancuronium bromide (Pavulon; Organon, Scarborough, Ontario, Canada; $1 \mathrm{mg} / \mathrm{kg}$ i.v., supplemented as necessary) and ventilated mechanically according to standard parameters (Kleinman and Radford, 1964). The spinal cord was covered with mineral oil (Marcol 72; Imperial Oil Limited, Montreal, Quebec, Canada) at $37.5^{\circ} \mathrm{C}$ to prevent drying. The temperature of the rat was maintained at $\sim 37.5^{\circ} \mathrm{C}$ using a heating lamp.

Electrical recording and data acquisition. Single-unit spikes were recorded extracellularly using seven-barrelled (overall tip diameter, 2-4 $\mu \mathrm{m})$ and single-barrelled $(1-2 \mu \mathrm{m})$ micropipettes. A solution of $2.7 \mathrm{M}$ $\mathrm{NaCl}$ was placed in the recording barrel (impedance 2-4 $\mathrm{M} \Omega$ measured at $1 \mathrm{kHz}$ with the tip submerged in saline). Single-unit recordings were made at depths ranging from 250 to $1300 \mu \mathrm{m}$ in the dorsal horn, representing all laminae of the dorsal horn; effects were without any clear differentiation as to sensitivities depending on depth. The raw data were amplified 10,000 times (DP-301 Differential Amplifier; Warner Instrument Corporation), displayed on an oscilloscope (Tektronix 5111), and stored on video cassette tapes using a digital data recorder that incorporated a digital pulse code modulation technique (VR-100A; Instrutech Corporation) and a conventional video cassette recorder. The signals were also relayed to a frequency counter/gating unit, which discriminated single units, based on spike amplitude, and counted the number of spikes per unit time (bin widths were $1 \mathrm{sec}$ ). All recordings were from single units. Sampling of extracellular recordings was done using the electrophysiological data acquisition program Spike 2 (version 2.02; Cambridge Electronic Design, Cambridge, UK) on an IBM Pentium computer. The 
rate of discharge (the output of the gating unit) was displayed continuously on a Grass 79D polygraph.

Functional classification of dorsal horn neurons. Functional classification of neurons was based on the responses to stimulation of their receptive fields in the ipsilateral hind limb by both noxious and innocuous stimuli. The following natural peripheral stimuli were used: (1) an air stream passed over the receptive field at a strength only sufficient to move the hairs, (2) light touch, (3) moderate pressure, (4) noxious mechanical stimulation using a calibrated clip $(21 \mathrm{~N})$, and (5) noxious thermal stimulation (measured to be $50^{\circ} \mathrm{C}$ ) using radiant heat. During experimentation, classification of the identified neurons was in three categories (Henry, 1976): (1) non-nociceptive neurons that responded only to non-noxious stimuli such as hair deflection, touch, and/or pressure (some receptive fields on the rat hindlimb did not have hair), (2) wide dynamic range neurons that responded to both noxious and innocuous stimuli, and (3) nociceptive-specific neurons that responded only to noxious mechanical and/or thermal stimulation. In addition, all the units that responded to the "noxious" range of mechanical and/or thermal stimulation showed a characteristic afterdischarge, as described previously (Henry, 1976). Non-nociceptive neurons were not used in this study; thus only wide dynamic range and nociceptive specific neurons were tested with formalin injection into the cutaneous receptive field. The sites of injection of formalin are represented schematically in the figures.

Formalin injection. Once stable ongoing activity of a wide dynamic range or nociceptive specific neuron was obtained, the receptive field of the ipsilateral hindpaw was injected with $50 \mu \mathrm{l}$ of $2.5 \%$ formalin subcutaneously using a 27 gauge syringe needle. Only one such injection was made in each experiment.

Drug administration. The nonpeptide NK-1 receptor antagonist, (2S,3S)-cis-2-(diphenylmethyl)- $N$-[(2-methoxyphenyl)methyl]-1-azabicyclo [2.2.2] octan-3-amine (CP-96,345) was administered intravenously 35-40 min after subcutaneous injection of formalin into the plantar receptive field of the hindpaw; information on the synthesis, properties, and bioavailability of this antagonist has been reported (McLean et al., 1991; Lowe et al., 1992). This time was considered appropriate as it was generally shortly after onset of the second phase of the excitatory response to subcutaneous injection of formalin. The rationale was to determine whether the second phase could be reversed once it had begun. CP-96,345 was administered intravenously in a single dose of 0.5 $\mathrm{mg} / \mathrm{kg}$ in saline. The inactive isomer CP-96,344 was given at the same dose in a similar manner in another group of rats. The results of both groups of rats were compared with responses of a control group that received no pharmacological manipulation beyond the formalin injection.

Data analysis. The total number of spikes was counted for $5 \mathrm{~min}$ periods, beginning $5 \mathrm{~min}$ before formalin injection; this prestimulus period thus represented the baseline level of activity. The mean of these counts for each period was calculated for each group of animals.

To calculate the effects of drug administration, neuronal activity in the 5 min period ending when formalin was injected was normalized to $100 \%$. Thus, the effects of CP-96,345, CP-96,344, or no pharmacological manipulation on neuronal activity subsequent to the injection were determined relative to the neuronal activity at that time.

To calculate significance, the mean \pm SEM percent values of the $5 \mathrm{~min}$ periods throughout the testing period of the formalin response of each of the three groups were compared with each other. Statistical analysis of the data was done using one-way ANOVA and Student-Newman-Keuls test. A difference in responses between groups was considered significant with a $p$ value $<0.05$.

\section{Autoradiographic studies}

Long-Evans hooded male rats, weighing 300-350 gm, were used in these experiments.

Behavioral studies. The methods followed for the formalin test were the same as those described above, with the exception that the concentration of formalin was 1 or $5 \%$.

Autoradiography. Following injection of either 1 or $5 \%$ formalin, the rats were decapitated at 5, 12, 25, or $60 \mathrm{~min}$. Control rats were not given the formalin injection. Each group consisted of 3 or 4 animals. After decapitation, the spinal cords were rapidly removed and snap frozen in 2-methylbutane at $-40^{\circ} \mathrm{C}$. Blocks of lumbar cord were mounted on cryostat chucks and cut into $20 \mu \mathrm{m}$ sections at $-18^{\circ} \mathrm{C}$. Sections were mounted on slides, dried overnight in a desiccator at $4^{\circ} \mathrm{C}$, and stored at $-80^{\circ} \mathrm{C}$. For the binding procedures, tissue sections were incubated for 90 $\mathrm{min}$ at room temperature in a buffer containing $50 \mathrm{~mm}$ Tris- $\mathrm{HCl}, \mathrm{pH} 7.4$,

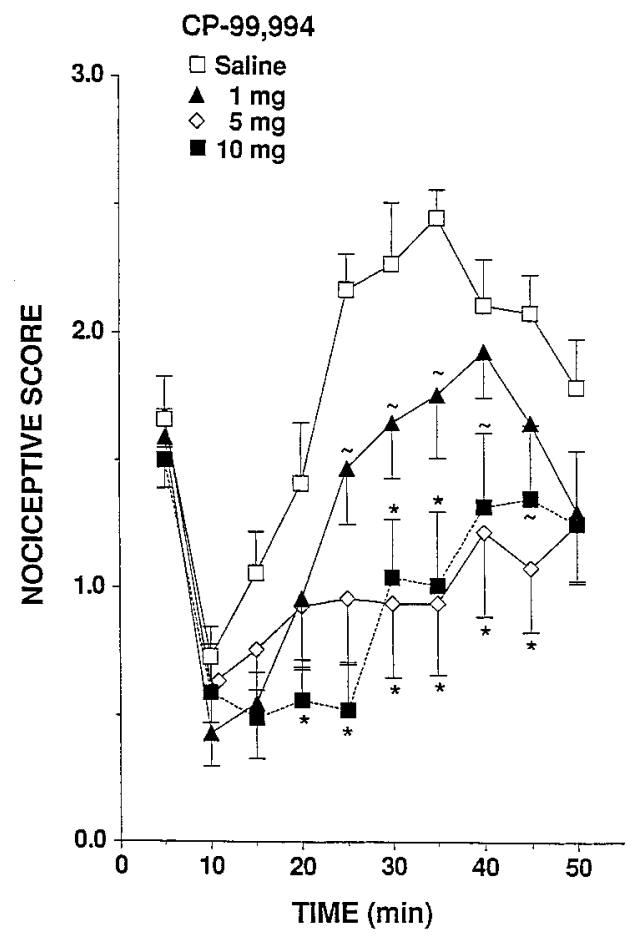

Figure 1. Effects on nociceptive scores of administration of different doses of CP-99,994 given subcutaneously before injection of formalin (50 $\mu \mathrm{l}$ of a $2.5 \%$ solution given at time 0 ) into the plantar surface of the ipsilateral hindpaw. Sprague Dawley rats were given saline $(n=10)$ or CP-99,994 in a dose of $1(n=10), 5(n=10)$, or $10(n=8) \mathrm{mg} / \mathrm{kg} 30 \mathrm{~min}$ before formalin injection. $\sim p<0.05 ;{ }^{*} p<0.01$ compared with the saline-treated group.

$3 \mathrm{~mm} \mathrm{MnCl} l_{2}, 0.02 \%$ BSA, $40 \mu \mathrm{g} / \mathrm{ml}$ bacitracin, $2 \mu \mathrm{g} / \mathrm{ml}$ chymostatin, 4 $\mu \mathrm{g} / \mathrm{ml}$ leupeptin, and $50 \mathrm{pm}\left[{ }^{125} \mathrm{I}\right] \mathrm{BH}$-substance P $(2200 \mathrm{Ci} / \mathrm{mmol}$; New England Nuclear, Boston, MA) for binding to NK-1 receptor sites. Nonspecific binding was assessed in the presence of $1 \mu \mathrm{M}$ substance $\mathrm{P}$ (Peninsula Laboratories, Belmont, CA). At the end of the incubation period, slides were washed four times $(1 \mathrm{~min}$ each) in Tris- $\mathrm{HCl}$ buffer, rinsed in cold distilled water, air-dried, and apposed to Hyperfilms for 7 d. Hyperfilms were developed, and autoradiograms were quantified densitometrically using an MCID (Imaging Research, St. Catharines, Ontario, Canada) image analysis system. The optical densities from laminae I and II of the dorsal horn of the lumbar spinal cord were converted into semiquantitative values expressed in femtomoles per milligram of tissue wet weight using appropriate radioactive microscales that were coexposed with the radiolabeled sections. All the data are expressed as mean $\pm \mathrm{SEM}$, and each value represents the mean of 5-12 sections from three rats.

\section{RESULTS}

\section{Behavioral studies}

Effects of different doses of CP-99,994 given before formalin injection

Figure 1 illustrates the results obtained from administration of different systemic doses of CP-99,994 on nociceptive scores in the formalin test when the antagonist was given $30 \mathrm{~min}$ before formalin injection. In general, there was no effect of any dose on the first phase of the response to injection, measured within the first $5 \mathrm{~min}$. However, the second phase was depressed variably, depending on the dose. The maximum effective dose was $5 \mathrm{mg} / \mathrm{kg}$ $(n=10)$, a dose of $10 \mathrm{mg} / \mathrm{kg}(n=8)$ having no further effect. When $1 \mathrm{mg} / \mathrm{kg}$ of CP-99,994 was given $(n=10)$, only a minor effect was seen. The ANOVA indicated a main effect of dose $\left(F_{(3,34)}=8.33 ; p<0.001\right)$ and a main effect of time $\left(F_{(9,306)}=\right.$ 


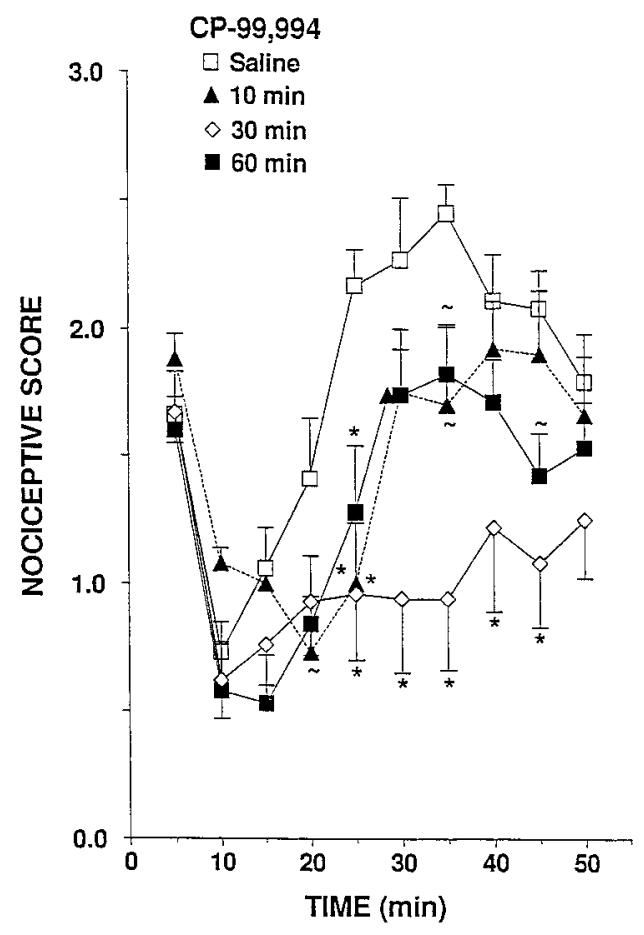

Figure 2. Effects on nociceptive scores of administration of $5 \mathrm{mg} / \mathrm{kg}$ of CP-99,994 subcutaneously at different times before injection of formalin in Sprague Dawley rats. Times of preadministration were $10(n=8), 30$ $(n=10)$, and $60(n=8)$ min before formalin injection. The saline group $(n=10)$ and the 30 min group were the same as in Figure 1. $\sim p<0.05$; ${ }^{*} p<0.01$ compared with the saline-treated group.

17.2; $p<0.001)$. There was also a dose $\times$ time interaction $\left(F_{(27,306)}=2.17 ; p<0.001\right)$. Post hoc comparisons indicated differences at levels of $p<0.05$ and 0.01 at different test times for the different dose groups, as indicated in Figure 1.

\section{Effects of time of preadministration of CP-99,994}

Regardless of the time between administration of the antagonist and formalin injection, there was no effect of systemic administration of $5 \mathrm{mg} / \mathrm{kg}$ of CP-99,994 on the first phase of the nociceptive response. However, the second phase was depressed, with the greater effect occurring when administration preceded formalin injection by $30 \mathrm{~min}(n=10)$, rather than by $10(n=8)$ or $60(n=8) \mathrm{min}$. The results obtained are illustrated in Figure 2, with the data from the group given $5 \mathrm{mg} / \mathrm{kg} 30 \mathrm{~min}$ before formalin injection taken from Figure 1 for comparison. The ANOVA indicated a main effect of injection time $\left(F_{(3,30)}=8.19\right.$; $p<0.001)$ and a main effect of test time $\left(F_{(9,270)}=19.5 ; p<\right.$ $0.001)$. There was also an injection treatment $\times$ test time interaction $\left(F_{(27,270)}=2.36 ; p<0.001\right)$. Post hoc comparisons indicated differences at levels of $p<0.05$ and 0.01 at different test times in the different injection time groups, as indicated in Figure 2.

\section{Effects of intrathecal administration of CP-99,994 or} CP-100,263 after formalin injection

At $\sim 10$ min after the second phase had begun, that is 20 min after formalin injection, the intrathecal administration of $20 \mu \mathrm{g}$ of CP-99,994 $(n=13)$ induced a rapid decrease in the amplitude of this second phase. When CP-100,263 was given in a similar manner $(n=6)$, behavioral scores showed the typical pattern. The data are illustrated in Figure 3, along with similar data from the control group given CSF $(n=6)$. There was no significant

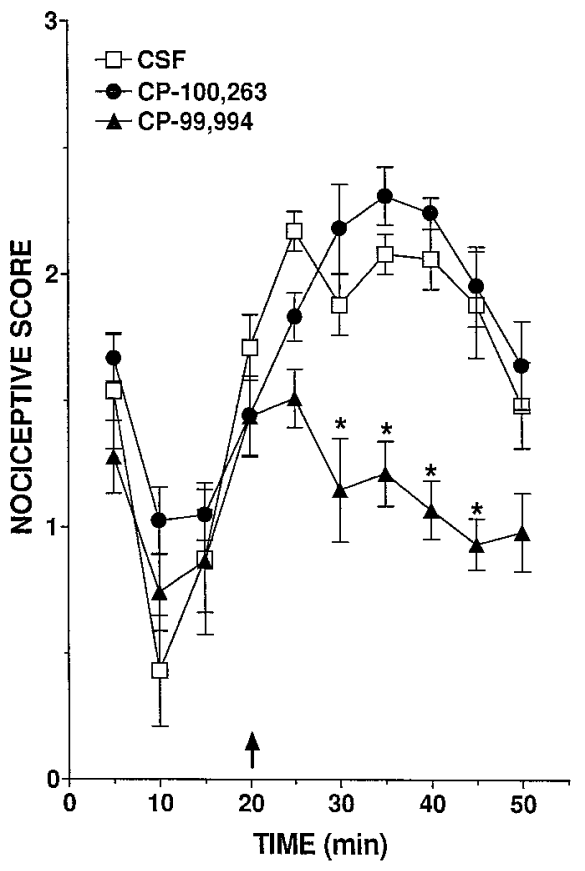

Figure 3. Effects on nociceptive scores of intrathecal administration of CP-99,994 20 min after injection of formalin in Sprague Dawley rats. Intrathecal administration of CSF $(n=6)$, of CP-99,994 $(20 \mu \mathrm{g} ; n=13)$, or of CP-100,263 (20 $\mu \mathrm{g} ; n=6)$ was immediately following the fourth time block, when the second phase of the nociceptive response had begun to be expressed. $\sim p<0.05$; $^{*} p<0.01$ compared with the CSF-treated group.

difference between the three groups up to 20 min after formalin injection. However, in the group treated with CP-99,994 an immediate decrease in nociceptive scores was seen at $25 \mathrm{~min}$, and this group remained lower than the other two groups for the remainder of the testing period. The ANOVA indicated a main effect of treatment $\left(F_{(1,17)}=10.33 ; p<0.001\right)$ and a main effect of test time $\left(F_{(9,153)}=10.06 ; p<0.001\right)$. There was also a time $\times$ test time injection effect $\left.\left(F_{(9,153)}=3.97\right] ; p<0.001\right)$. Post hoc comparison indicated a difference of $p<0.05$ and 0.01 for the group given CP-99,994 at the times indicated in Figure 3.

\section{Electrophysiological studies}

Effects of subcutaneous injection of formalin into the cutaneous receptive field

Subcutaneous injection of $2.5 \%$ formalin $(50 \mu \mathrm{l})$ into the plantar surface of one hindpaw of the rat induced a biphasic excitatory effect on the firing frequency in all nine of the neurons tested (Figs. $4 A, 5 A$ ). The first phase began immediately after injection of formalin and persisted for $\sim 5 \mathrm{~min}$. This was followed by a decrease in neuronal activity that lasted for $\sim 25-30 \mathrm{~min}$. At this time a second phase of increased activity began. This second excitatory phase was longer-lasting, remaining up to $\sim 100 \mathrm{~min}$ after formalin injection. Figure $4 A$ shows the effect of injection of formalin into the cutaneous receptive field on the firing frequency of a wide dynamic range neuron. The immediate increase in firing rate of wide dynamic range neurons before the first phase response to formalin injection into the receptive field is the excitatory response of the neuron to mechanical pressure of the cutaneous receptive field by the experimenter lightly holding the paw while injecting formalin. This is not a response to formalin because this effect did not occur in nociceptive-specific neurons 


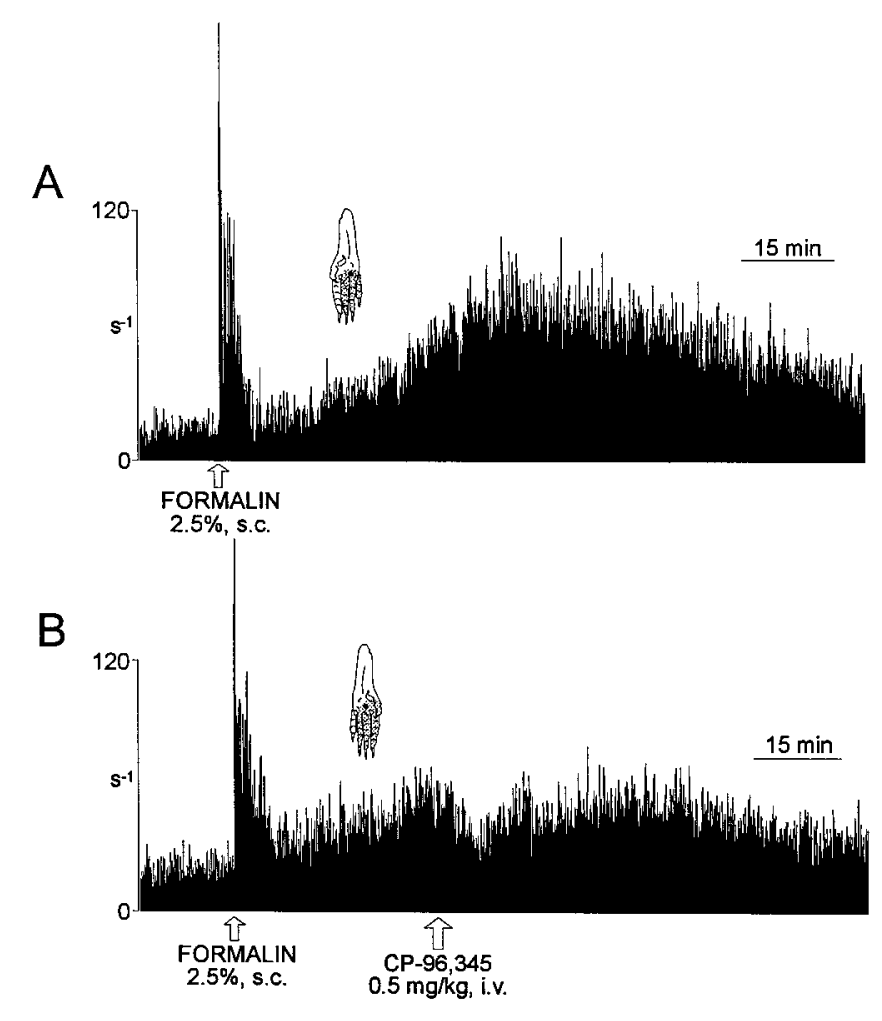

C

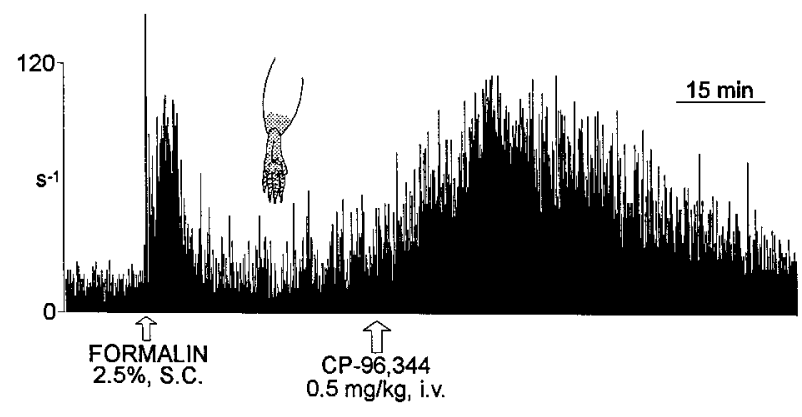

Figure 4. Ratemeter histograms from electrophysiological experiments showing responses of three dorsal horn neurons to formalin injection into the left or right hindpaw. $A$, Subcutaneous injection of formalin (50 $\mu \mathrm{l}$ of $2.5 \%$ ) into the plantar surface of the right hindpaw (represented by a small black circle on the shaded cutaneous receptive field) produced an increase in neuronal activity of a wide dynamic range neuron $(1072 \mu \mathrm{m})$ followed by a decrease in the firing frequency that lasted to $\sim 20 \mathrm{~min}$. This was followed in turn by a longer-lasting second increase in neuronal activity that persisted for $>70 \mathrm{~min}$. The vertical axis shows the firing frequency; each bin represents the firing frequency of the neuron in spikes per second. The horizontal axis is time. $B$, Intravenous administration of the NK-1 receptor antagonist CP-96,345 $(0.5 \mathrm{mg} / \mathrm{kg})$ depressed the increase in neuronal activity of the response of a wide dynamic range neuron $(744 \mu \mathrm{m})$ when given $35-40 \mathrm{~min}$ after formalin injection. $C$, Intravenous administration of the inactive isomer CP-96,344 $(0.5 \mathrm{mg} / \mathrm{kg})$ had no effect on the excitatory response of a wide dynamic range neuron $(296 \mu \mathrm{m})$ to injection of formalin. The transient increase in neuronal activity immediately before the first phase of the formalin response is the excitatory response of this wide dynamic range neuron to the hindpaw being held by the experimenter to administer the formalin injection.

tested with injection of formalin in the cutaneous receptive field. The biphasic nature and duration of the increased activity following formalin injection was observed in one nociceptive specific neuron and eight wide dynamic range neurons. The firing frequency during the inhibitory period (between the two excitatory phases) was generally greater than the ongoing baseline activity before formalin injection. This was seen consistently in recordings of most neurons (Figs. $4 A-C, 5 A$ ).

\section{Effects of intravenous administration of CP-96,345 or CP-96,344 after formalin injection}

Figure $4 B$ illustrates the effect of intravenous administration of $0.5 \mathrm{mg} / \mathrm{kg} \mathrm{CP}-96,345$ on the response of a wide dynamic range neuron to subcutaneous formalin injection. CP-96,345 was given at 35-40 min after formalin injection, during the initial part of the increase in neuronal activity of the second phase. CP-96,345 depressed any subsequent increase in neuronal activity. The inhibitory effect of CP-96,345 on the second phase of the formalin response was observed in 9 of the 10 wide dynamic range neurons tested.

Figure $5 A$ reveals a significant depressant effect of CP-96,345 on the second period of excitation in the response to formalin injection. Figure $5 B$ shows the time course of the second phase of the formalin response beginning $40 \mathrm{~min}$ after formalin injection, the time of intravenous administration of CP-96,345 or CP96,344. Each value represents the normalized mean number of spikes for each 5 min period expressed as a percent of the mean number of spikes at 40 min after injection. Comparison of the groups reveals a significant difference in the percent response of neurons between rats given CP-96,345 and those given the inactive isomer CP-96,344 ( $p<0.01$ at 45, 50, 55, and $60 \mathrm{~min}$ ). Comparison of the group that received CP-96,345 and the group that received no pharmacological manipulation reveals a significant difference ( $p<0.001$ at 45 and $50 \mathrm{~min} ; p<0.01$ at 55 and $60 \mathrm{~min})$.

Administration of $0.5 \mathrm{mg} / \mathrm{kg}$ CP-96,344 in a similar manner was without effect on the second excitatory phase in any of the eight wide dynamic range neurons tested (Figs. $4 C, 5 A$ ). The amplitude and duration of the second phase of the formalin response of these neurons in rats given CP-96,344 were no different from the responses of neurons in rats that received no pharmacological manipulation (compare Fig. 4A, $C$, with Fig. 5A,B).

\section{Binding studies \\ Behavioral studies}

Nociceptive scores following injection of either 1 or $5 \%$ formalin to Long-Evans hooded rats are shown in Figure 6, $A$ and $B$, respectively. Both concentrations of formalin induced the typical biphasic nociceptive behavior. The early phase occurred at $5 \mathrm{~min}$ and was followed by a period of relatively low nociceptive scores and a subsequent nociceptive phase starting at $\sim 20 \mathrm{~min}$ after formalin injection and continuing beyond the completion of testing at $60 \mathrm{~min}$.

As expected, the response was concentration-dependent. In the group injected with $1 \%$ formalin (Fig. $6 A$ ), the mean maximum nociceptive score in the first excitatory phase was 1.3 , and in the second excitatory phase it was $\sim 1.5$. In the group given $5 \%$ formalin (Fig. $6 B$ ), the maximum response in the first excitatory phase was 2.2, whereas in the second it was 2.4. There was a significant difference in nociceptive scores between rats given 1 and $5 \%$ formalin at $5 \mathrm{~min}$ and then from $30 \mathrm{~min}$ onward, through the rest of the testing period. Thus, in general, the nociceptive scores after injection of $5 \%$ formalin were higher than those after $1 \%$. 

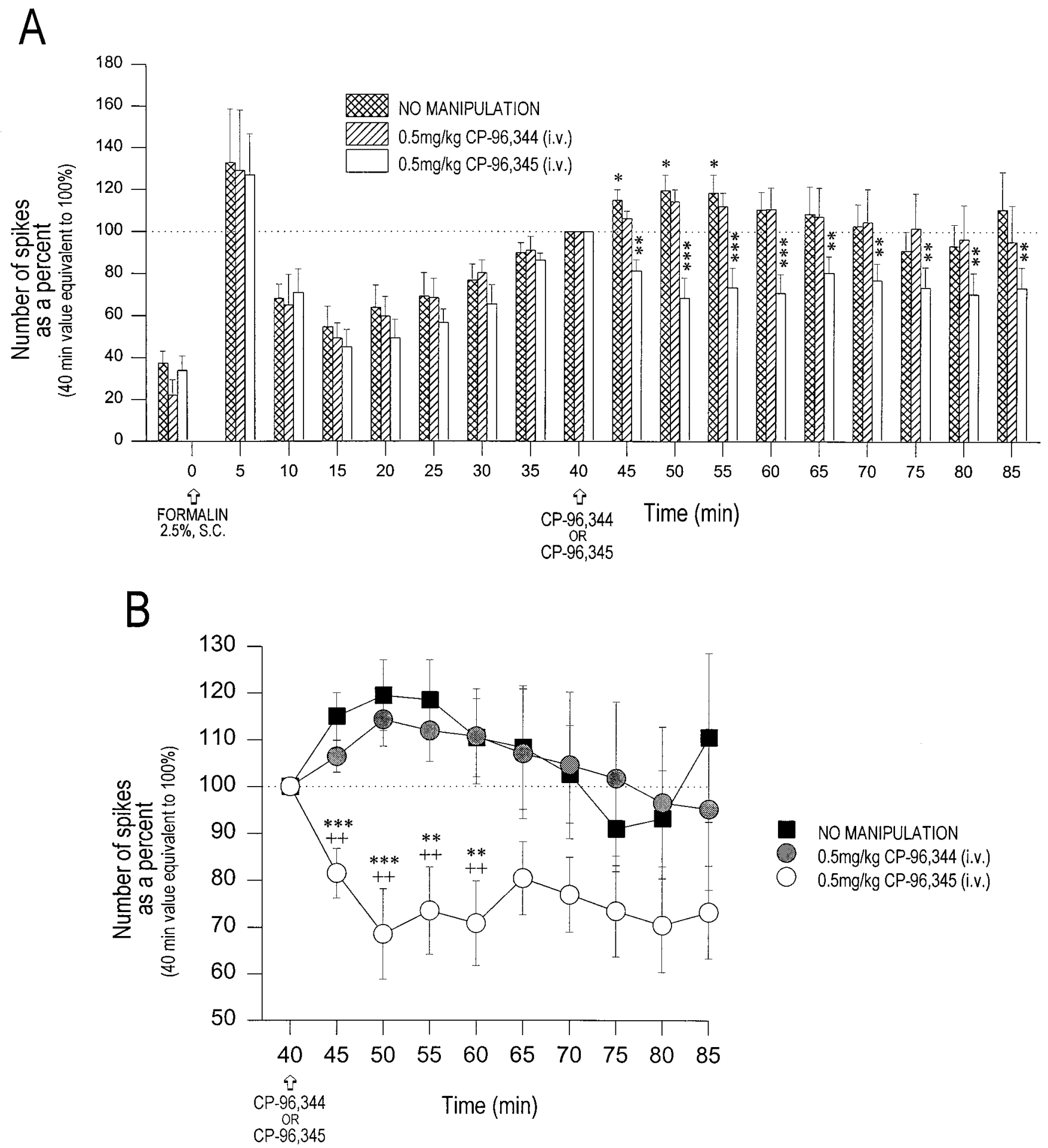

Figure 5. Averaged data from the three groups of rats given formalin into the ipsilateral hindpaw to illustrate effects of systemic administration of CP-96,345 and of CP-96,344 on the second phase of excitation in the response to formalin injection. A, Time histogram. The cross-hatched histogram represents animals that received no pharmacological manipulation $(n=9)$, the diagonal-hatched histogram represents the group of rats given CP-96,344 $(n=8)$, and the clear histogram represents animals treated with the NK-1 receptor antagonist CP-96,345 $(n=9)$ at 40 min after formalin injection. The vertical axis represents the mean number of spikes in 5 min periods, normalized to the value at 40 min. The horizontal axis represents time. For each time after $40 \mathrm{~min}$, a comparison was made in each treatment group between the normalized mean number of spikes at that point and $100 \%$. $\left({ }^{*} p<0.05\right.$; $\left.{ }^{* *} p<0.01 ; * * *<0.001\right) B$, Graph showing the time course of the mean changes in rate of discharge beginning 40 min after formalin injection, the time of intravenous administration of CP-96,345 or CP-96,344. Each value represents the normalized mean number of spikes for each 5 min period expressed as a percent of the number of spikes at $40 \mathrm{~min}$ after formalin injection. Comparison of the groups reveals a significant difference between the number of spikes from neurons in rats treated with CP-96,345 compared with the number from rats treated with the inactive isomer CP-96,344 $(++p<$ 0.01 at $45,50,55$, and $60 \mathrm{~min}$ ). Comparison of the group of rats that received no pharmacological manipulation and the group that received CP-96,345 reveals a significant difference. ${ }^{* *} p<0.001$ at 45 and $50 \mathrm{~min} ;{ }^{* *} p<0.01$ at 55 and $60 \mathrm{~min}$. 

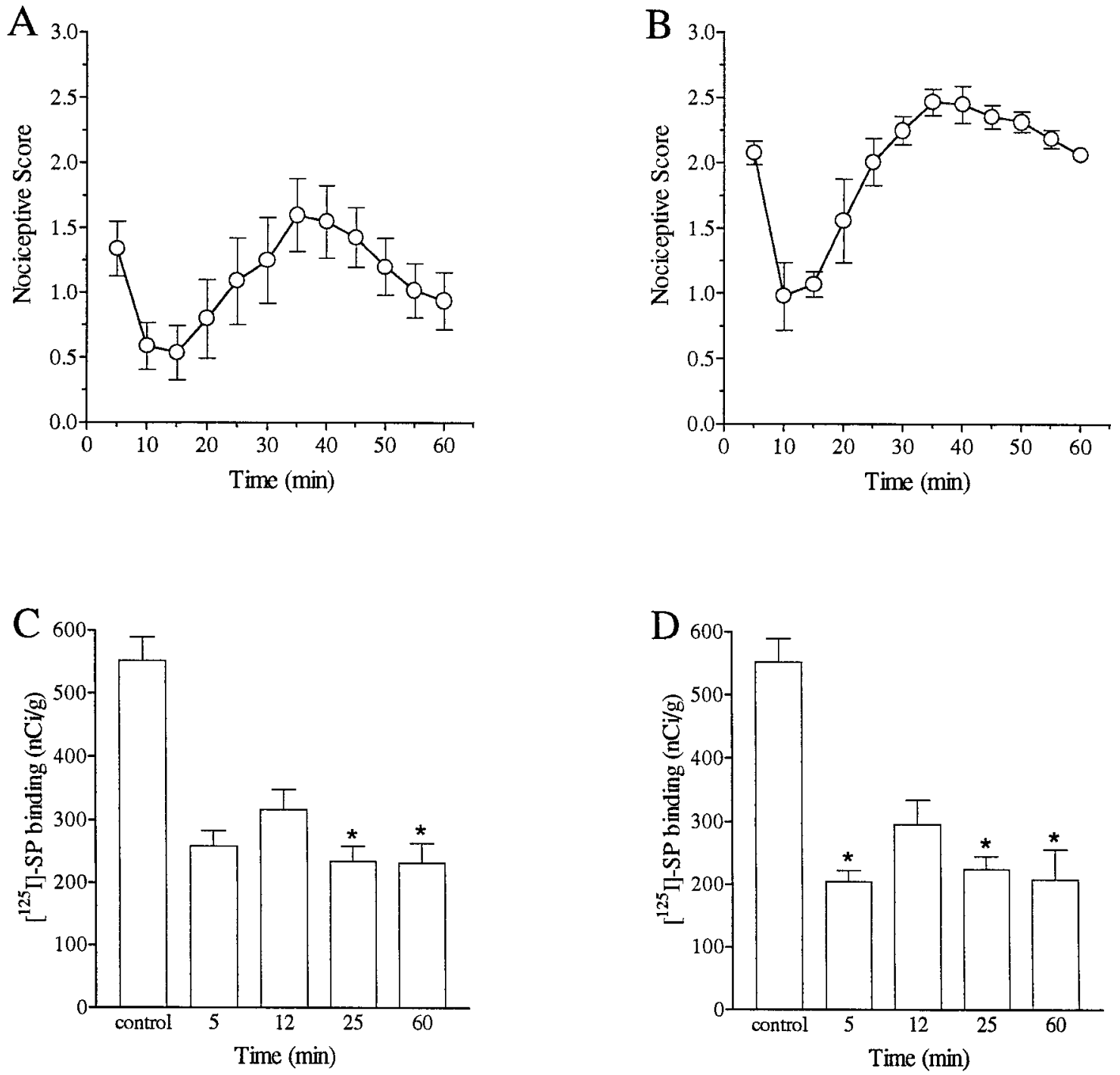

Figure 6. Nociceptive scores in Long-Evans hooded rats after 1\% $(A)$ and 5\% $(B)$ formalin injection into the plantar surface of the ipsilateral hindpaw. $C$ and $D$ show quantitative autoradiographic analysis of the distribution of [ ${ }^{125} \mathrm{I}$ ] BH-substance $\mathrm{P}$ in laminae I and II of the dorsal horn of the lumbar spinal cord. Specific binding is expressed as mean \pm SEM, in nanocuries per gram obtained from 5-12 sections from three rats in each group. * $p<0.05$ as compared with the $12 \mathrm{~min}$ time period. Values of the scale bar are expressed in femtomoles per gram tissue wet weight.

\section{Quantification of autoradiograms}

Examples of the quantitated images of autoradiograms used for analysis of binding are shown in Figure 7. Samples are from an untreated rat from the control group and from individual rats killed at 5, 12, and 25 min after intraplantar injection of 1 or $5 \%$ formalin. The image from the control cord shows that binding extended throughout the dorsal horn. The changes in binding are seen in both the superficial and the deep laminae at all time points after formalin injection.

Figure $6, C$ and $D$, illustrates the combined data. The histograms show that compared with controls there is less $\left[{ }^{125} \mathrm{I}\right] \mathrm{BH}-$ substance $\mathrm{P}$ binding in the dorsal horn of the spinal cords of the groups given 1 or $5 \%$ formalin injections. No significant difference was found at any time between these two groups. Quantification of the data show that for both test groups binding of $\left[{ }^{125} \mathrm{I}\right] \mathrm{BH}$-substance $\mathrm{P}$ was significantly lower than in untreated controls at all time periods sampled. ANOVA revealed a significant effect of time after formalin injection for both $1 \%\left(F_{(4,37)}=\right.$ $19.8 ; p<0.001)$ and $5 \%\left(F_{(4,36)}=19.6 ; p<0.001\right)$ groups.
In the case of $1 \%$ formalin, there was no significant difference in binding between 5 and 12 min samples $(p>0.05)$. However, at 25 and $60 \mathrm{~min}$, binding of $\left[{ }^{125} \mathrm{I}\right] \mathrm{BH}$-substance $\mathrm{P}$ was significantly lower than that at $12 \min (p<0.05)$. In the case of $5 \%$ formalin, the binding at all other times, i.e., at 5, 25, and $60 \mathrm{~min}$, was significantly lower than at $12 \min (p<0.05)$. Thus, in the $5 \%$ group, there was more binding of the exogenous ligand at $12 \mathrm{~min}$ than at the other times after formalin injection.

\section{DISCUSSION}

\section{Formalin test}

The results of this study indicate that when the nonpeptide NK-1 receptor antagonist CP-99,994 is given subcutaneously it has a dose-related depressant effect on the second phase, but not the first phase, of the nociceptive response in the formalin test. The dose-response curve indicates that the maximum effect is reached with $5 \mathrm{mg} / \mathrm{kg}$ subcutaneously and that the effect is greatest when the antagonist is given $30 \mathrm{~min}$ before formalin is injected into the paw, i.e., $50 \mathrm{~min}$ before the second phase begins. These 


\section{CONTROL}

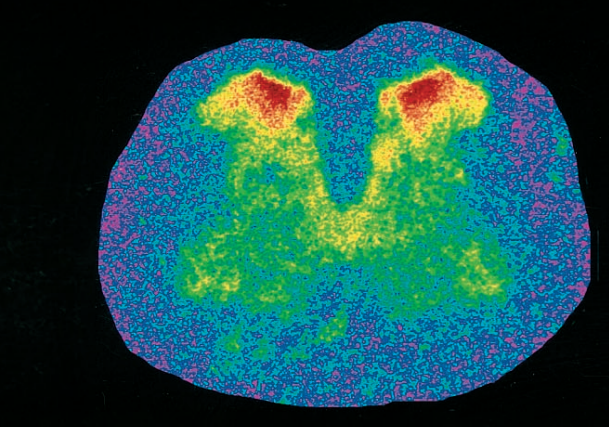

$1 \%$

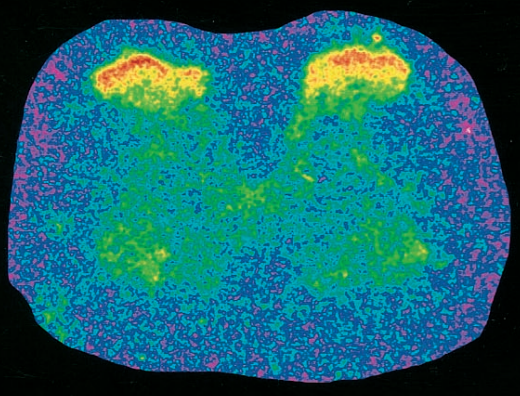

\section{$5 \mathrm{~min}$}

FORMALIN

\section{NON-SPECIFIC}

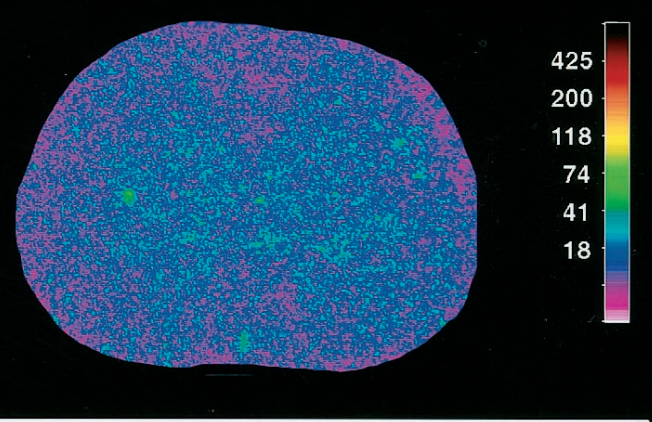

$5 \%$

\section{$12 \mathrm{~min}$}
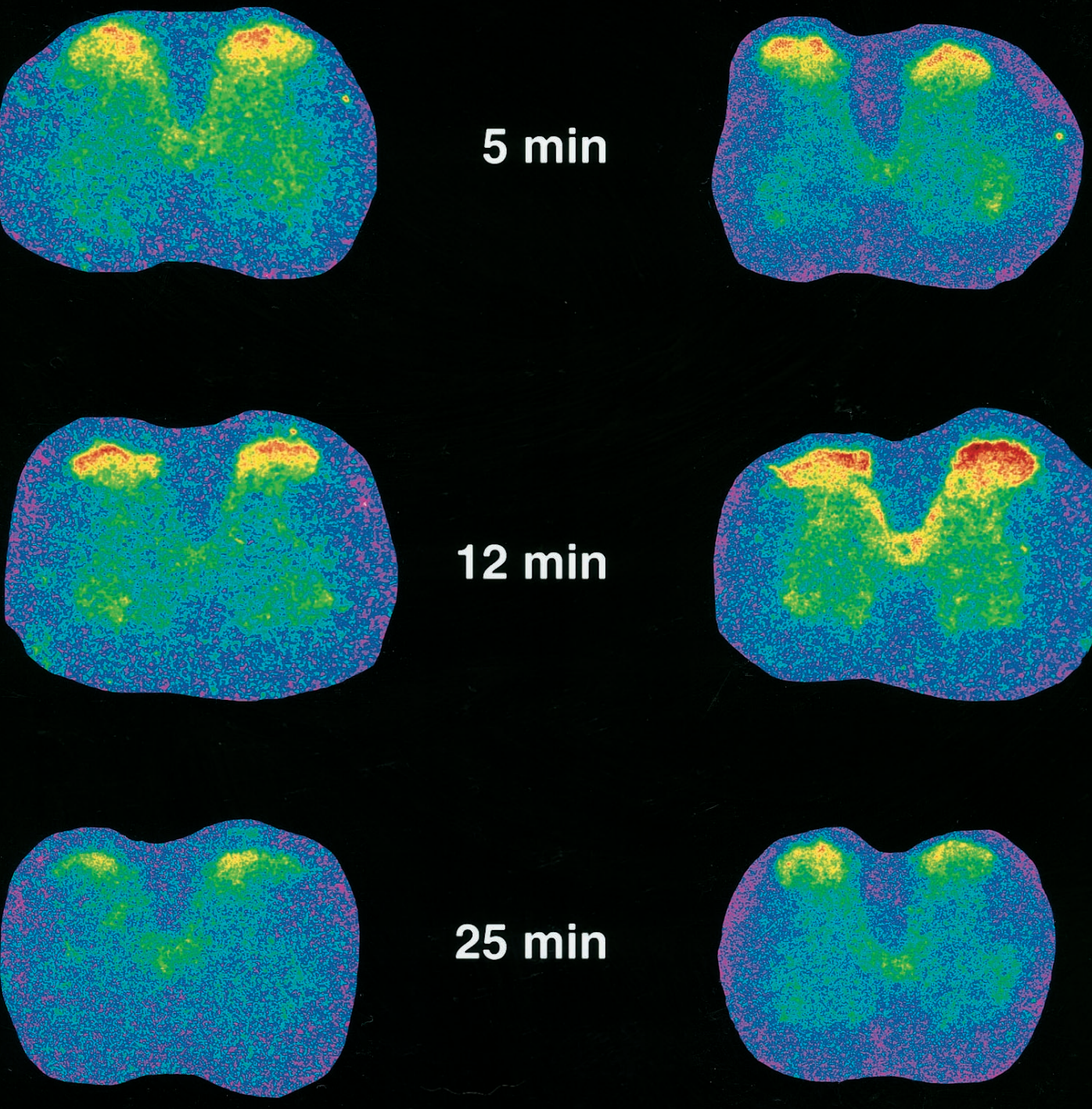

\section{5 min}
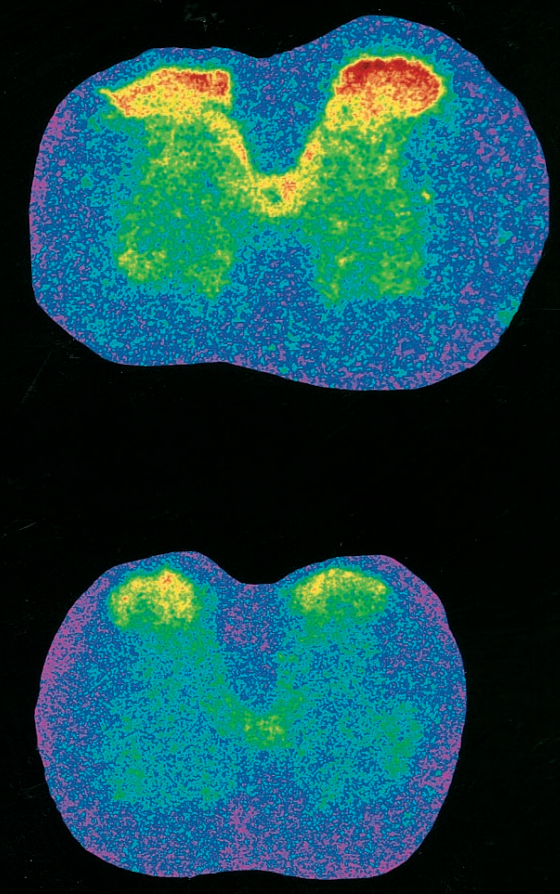

Figure 7. Color-coded autoradiograms of binding of $\left[{ }^{125} \mathrm{I}\right] \mathrm{BH}$-substance $\mathrm{P}$ in the lumbar spinal cord of the rat, as yielded by image analysis. Times indicated are the times of killing after formalin injection. The $60 \mathrm{~min}$ group is not represented because the binding was not different from that at 25 min (Fig. 6C,D). 
data thus support the earlier suggestion that when NK-1 receptor antagonists are given before formalin injection, they block the second phase but not the first phase of the formalin test (Yamamoto and Yaksh, 1991; Yashpal et al., 1993). The data also indicate, though, that the time of onset of the effects of systemic administration of CP-99,994 is too slow for studies in which NK-1 receptor block is to be attempted after formalin injection.

When CP-99,994, but not the inactive isomer, was given intrathecally after formalin injection, in fact during the second phase, the subsequent second phase nociceptive scores were significantly attenuated. This observation, that the second phase can be reversed by an NK-1 receptor antagonist, differs from that of an earlier study (Yamamoto and Yaksh, 1991), which reported that intrathecal administration of CP-96,345, 5 min after formalin injection, had no effect on the nociceptive scores during the second excitatory phase. This difference regarding reversal of the nociceptive response during the second phase is important. It raises the issue of the mechanisms bringing about the second phase of the nociceptive response to formalin injection, which has variously been attributed to central sensitization and to sustained afferent input. Some investigators have suggested that the second phase is caused in part by short-term input during the first phase (Coderre et al., 1990; Yamamoto and Yaksh, 1992), which causes a so-called central sensitization (Coderre and Melzack, 1992; Yamamoto et al., 1993; Abram et al., 1994; Goto et al., 1994). This central sensitization is sometimes thought to have been produced by glutamate (Coderre and Melzack, 1992; Yamamoto and Yaksh, 1992; Malmberg and Yaksh, 1993; Vaccarino et al., 1993) and/or substance P (Yamamoto and Yaksh, 1991; Traub, 1996) released during the first phase. This concept is inconsistent with the time course of the effects of substance P when applied by iontophoresis onto single neurons in vivo (Henry, 1976) and on the tail flick reflex when given intrathecally (Yashpal et al., 1982; Cridland and Henry, 1986). In both paradigms the effects peak at $\sim 1 \mathrm{~min}$, rather than at 20-60 min as this interpretation would suggest. Nonetheless, our data are supported by a recent publication reporting that administration of CP-99,994 after intraarticular injection of inflammatory agents blocks the ensuing decrease in paw withdrawal latency and the pain-related behaviors (Sluka et al., 1997).

Other investigators have suggested that the second phase may be caused by continued afferent fiber input throughout the period of the second phase. This suggestion came because subcutaneous injection of formalin causes C-fiber primary afferents to discharge in two phases, which correspond temporally to the two phases of the behavioral responses to formalin injection (Dallel et al., 1995; McCall et al., 1996; Puig and Sorkin, 1996). This suggestion is strengthened by the observation that in the formalin test in the gerbil, systemic administration of an NK-1 receptor antagonist which crosses the blood-brain barrier inhibits the second phase, whereas an antagonist that does not have access to the CNS is without effect in this test (Rupniak et al., 1996).

Although these two possible mechanisms are not necessarily mutually exclusive, the attenuation of the nociceptive response by the NK-1 receptor antagonist in the present study indicates that the second phase is at least partially caused by tonic actions of substance $\mathrm{P}$ or a related ligand at the NK-1 receptor. This may be caused by continuous release of the ligand, to persistence of the ligand in the synaptic cleft or possibly to other mechanisms. Irrespective of this, though, on the basis of the results presented in this study, we propose that the nociceptive scores in the second phase of the formalin test are caused at least in part by continuous activation of NK-1 receptors.

\section{Electrophysiological study}

Data from the electrophysiological study confirm that subcutaneous injection of dilute formalin into the cutaneous receptive field gives rise to a three-phase response in dorsal horn wide dynamic range neurons. This response consists of (1) an initial excitatory component lasting only a few minutes, followed by (2) a period of reduced activity lasting 25-30 $\mathrm{min}$, and finally (3) a second excitatory response lasting $>70 \mathrm{~min}$. The second excitatory response seen here is longer than that reported from other electrophysiological studies (Chapman and Dickenson, 1993; Diaz and Dickenson, 1997). It is also longer than the second phase in the formalin test (Dubuisson and Dennis, 1977), possibly because descending controls were interrupted by the spinal transection in the electrophysiological part of the present study.

More importantly, the results indicate that when CP-96,345 is given during the second excitatory phase, this phase is attenuated. As this effect is not shared by the inactive enantiomer, CP-96,344, the data support the earlier suggestion that activation of NK-1 receptors contributes to this second excitatory phase of the response of dorsal horn nociceptive neurons to subcutaneous injection of formalin in the rat (Chapman and Dickenson, 1993).

Although the earlier study has already implicated NK-1 receptors in the second excitatory phase of the response to injection of formalin on the basis of preadministration of an NK-1 receptor antagonist, the important part of the present electrophysiological study is that it indicates that when CP-96,345 is given after formalin injection, during the onset of the second excitatory phase, this phase is attenuated. Thus, the effects of the antagonist on the second excitatory phase could not have included mechanisms altered during the first excitatory phase. These data therefore parallel the results obtained from the behavioral paradigm of this report. Both series of experiments show a reversal of the second excitatory response to formalin injection when an NK-1 receptor antagonist is given, not before or just after formalin injection, but during the onset of the second phase. This evidence suggests clearly not only the activation of NK-1 receptors following the noxious peripheral stimulus, but it also indicates the continuous presence of a ligand at these receptors throughout the period of recording electrophysiologically or testing behaviorally. Accordingly, the data support the proposal presented above that the second phase is at least partially caused by tonic actions of substance $\mathrm{P}$ or a related ligand at the NK-1 receptor, whether this is caused by continuous release, persistence of the ligand in the synaptic cleft, or other mechanisms.

\section{Autoradiographic study}

The autoradiographic data indicate an inverse relation between nociceptive scores and binding of exogenous substance P following intraplantar injection of formalin into a rat hindpaw. In view of our previous report that binding of exogenous substance P was decreased by noxious thermal stimulation of a hindlimb (Yashpal et al., 1994), we suggest that this binding is also decreased in the present experiments by noxious chemical stimulation of a hindpaw. Both stimuli provoke a physiological response mediated at the spinal cord level by activation of NK-1 receptors (Yamamoto and Yaksh, 1991; Birch et al., 1992; Yashpal et al., 1993, 1995; Traub, 1996). Thus, the decrease in density of $\left[{ }^{125} \mathrm{I}\right] \mathrm{BH}$-substance $\mathrm{P}$ receptor binding can be presumed to correlate with the release of an endogenous ligand for the NK-1 receptor, such as substance 
P. Such a proposal is not without precedent. A similar occupation of receptors by an endogenous ligand has been reported for opiate receptors in the brain of the rat (Seeger et al., 1984; Wagner et al., 1990; Ruiz-Gayo et al., 1992).

An interesting difference exists in the time course of the displaced binding between the previous study with noxious thermal stimulation and the present study with noxious chemical stimulation. The noxious thermal stimulus produced a transient response lasting $<5 \mathrm{~min}$, and the binding displacement was depressed most at $1 \mathrm{~min}$ after the stimulus, with a partial return at $10 \mathrm{~min}$ and a full return at $60 \mathrm{~min}$. In the present experiments, the binding displacement also followed the time course of the nociceptive response, in that the nociceptive scores were still elevated $60 \mathrm{~min}$ after formalin injection, and displacement of binding continued at $\sim 40 \%$ of control at $60 \mathrm{~min}$. Thus, in each case, the displacement of binding correlated temporally with the physiological response.

The prolonged time course of the decrease in binding in this study suggests that the second phase of the formalin test may be associated with sustained occupation of NK-1 receptors and thus that the second phase may be caused at least in part by continued activation of NK-1 receptors. Although this possibility is at odds with previous reports that administration of the NK-1 receptor antagonist CP-96,345 after injection of formalin into the hindpaw fails to alter the second phase of the nociceptive response (Yamamoto and Yaksh, 1991; Sakurada et al., 1993b; Traub, 1996), the binding data are consistent with our observations in this study that intrathecal administration of CP-99,994 reverses the nociceptive response in the second phase of the formalin test and that systemic administration of CP-96,345 reverses the second excitatory phase of the response of spinal nociceptive neurons to subcutaneous injection of formalin. Therefore, our binding data support the proposal above that the second phase may be caused at least in part by continuous activation of NK-1 receptors.

The present results may also be interpreted to support the concept of tonic input from primary afferents during the second phase because binding displacement, which the previous study showed was not prolonged $>10$ min (Yashpal et al., 1994), was still occurring in the present study 25 min after formalin injection.

The bilateral decrease in binding is difficult to explain. However, it is consistent with previous reports of bilateral changes in [ $\left.{ }^{125} \mathrm{I}\right] \mathrm{BH}-$ substance $\mathrm{P}$ binding after noxious thermal stimulation (Yashpal et al., 1994), in 2-deoxyglucose metabolic activity following formalin injection (Aloisi et al., 1993), and in a rat model of peripheral mononeuropathy (Mao et al., 1992), as well as c-fos expression after formalin injection (Herdegen et al., 1991) and noxious thermal stimulation (Williams et al., 1990).

\section{General conclusions}

Evidence is presented that indicates that the second phase of the responses to subcutaneous injection of formalin is caused at least partially by tonic activation of NK-1 receptors. This is an important consideration as it contradicts the previous suggestion that intrathecal administration of an NK-1 receptor antagonist after formalin injection does not alter the second phase in the formalin test (Yamamoto and Yaksh, 1991; Traub, 1996).

Our data do not allow us to comment directly on whether the tonic activation of NK-1 receptors is caused by tonic release from primary afferents throughout the second phase, to a temporally limited release of substance $\mathrm{P}$, for example only during the first phase, but a slow removal or breakdown of substance $\mathrm{P}$, or to any other mechanism. However, in view of evidence from other laboratories that after injection of formalin into the paw (Puig and Sorkin, 1996) or into the peripheral receptive field (McCall et al., 1996) C-fiber afferent activity shows a biphasic excitation similar in time course to the two phases of the formalin test. In addition, when lidocaine was given into the formalin injection site just before formalin was given, the first phase was blocked, yet the second phase still occurred (Dallel et al., 1995). Thus, tonic activation from primary afferent fibers throughout the second phase seems to be at least one mechanism to account for the second excitatory phase. If this is indeed the case, then it can be concluded that at least some of the persistent nociceptive effects associated with inflammatory inputs, or at least those provoked by subcutaneous injection of formalin, are mediated via continuous activation of NK-1 receptors at the level of the spinal dorsal horn by continuous or tonic primary afferent input. As we indicate in the introductory remarks, the formalin test is often used as a model of acute and tonic pain. The present data support a role of continuous activation of $\mathrm{NK}-1$ receptors in maintenance of tonic pain. Thus, we suggest that the hyperexcitability that characterizes tonic pain (Lautenbacher et al., 1995; Rossi and Decchi, 1997; Bakke et al., 1998) may be at least partly caused by continuous activation of NK-1 receptors (Svensson et al., 1998).

\section{REFERENCES}

Abbadie C, Taylor BK, Peterson MA, Basbaum AI (1997) Differential contribution of the two phases of the formalin test to the pattern of c-fos expression in the rat spinal cord: studies with remifentanil and lidocaine. Pain 69:101-110.

Abram SE, Marsala M, Yaksh TL (1994) Analgesic and neurotoxic effects of intrathecal corticosteroids in rats. Anesthesiology 81:1198-1205.

Aloisi AM, Porro CA, Cavazzuti M, Baraldi P, Carli G (1993) "Mirror pain" in the formalin test: behavioral and 2-deoxyglucose studies. Pain $55: 267-273$

Bakke M, Hu JW, Sessle BJ (1998) Involvement of NK-1 and NK-2 tachykinin receptor mechanisms in jaw muscle activity reflexly evoked by inflammatory irritant application to the rat temporomandibular joint. Pain 75:219-227.

Birch PJ, Harrison SM, Hayes AG, Rogers H, Tyers MB (1992) The non-peptide $\mathrm{NK}_{1}$ receptor antagonist, $( \pm)$-CP-96,345, produces antinociceptive and anti-oedema effects in the rat. $\mathrm{Br} \mathrm{J}$ Pharmacol 105:508-510.

Chapman V, Dickenson AH (1993) The effect of intrathecal administration of RP67580, a potent neurokinin 1 antagonist on nociceptive transmission in the rat spinal cord. Neurosci Lett 157:149-152.

Chapman V, Buritova J, Honoré P, Besson JM (1996) Physiological contributions of neurokinin 1 receptor activation, and interactions with NMDA receptors, to inflammatory-evoked spinal c-Fos expression. J Neurophysiol 76:1817-1827.

Coderre TJ, Melzack R (1992) The contribution of excitatory amino acids to central sensitization and persistent nociception after formalininduced tissue injury. J Neurosci 12:3665-3670.

Coderre TJ, Yashpal K (1994) Intracellular messengers contributing to persistent nociception and hyperalgesia induced by L-glutamate and substance $\mathrm{P}$ in the rat formalin pain model. Eur $\mathrm{J}$ Neurosci 6:1328-1334.

Coderre TJ, Vaccarino AL, Melzack R (1990) Central nervous system plasticity in the tonic pain response to subcutaneous formalin injection. Brain Res 535:155-158.

Coderre TJ, Yashpal K, Henry JL (1994) Specific contribution of lumbar spinal mechanisms to persistent nociceptive responses in the formalin test. NeuroReport 5:1337-1340.

Cridland RA, Henry JL (1986) Comparison of the effects of substance $\mathrm{P}$, neurokinin A, physalaemin and eledoisin in facilitating a nociceptive reflex in the rat. Brain Res 381:93-99.

Dallel R, Raboisson P, Clavelou P, Saade M, Woda A (1995) Evidence for a peripheral origin of the tonic nociceptive response to subcutaneous formalin. Pain 61:11-16.

Diaz A, Dickenson AH (1997) Blockade of spinal N- and P-type, but not L-type, calcium channels inhibits the excitability of rat dorsal horn 
neurones produced by subcutaneous formalin inflammation. Pain 69:93-100.

Dubuisson D, Dennis SG (1977) The formalin test: a quantitative study of the analgesic effects of morphine, meperidine and brain stem stimulation in rats and cats. Pain 4:161-174.

Goto T, Marota JJA, Crosby G (1994) Pentobarbitone, but not propofol, produces pre-emptive analgesia in the rat formalin model. Br J Anaesth 72:662-667.

Henry JL (1976) Effects of substance P on functionally identified units in cat spinal cord. Brain Res 114:439-451.

Herdegen T, Tölle TR, Bravo R, Zieglgänsberger W, Zimmermann M (1991) Sequential expression of JUN B, JUN D and FOS B proteins in rat spinal neurons: cascade of transcriptional operations during nociception. Neurosci Lett 129:221-224.

Kleinman LI, Radford EP (1964) Ventilation standards for small mammals. J Appl Physiol 19:360-362.

Lautenbacher S, Roscher S, Strian F (1995) Tonic pain evoked by pulsating heat: temporal summation mechanisms and perceptual qualities. Somatosens Mot Res 12:59-70.

Lowe III JA, Drozda SE, Snider RM, Longo KP, Zorn SH, Morrone J, Jackson ER, McLean S, Bryce DK, Bordner J, Nagahisa A, Kanai Y, Suga O, Tsuchiya M (1992) The discovery of (2S,3S)-cis-2(diphenylmethyl)- $N$ - [(2-methoxyphenyl)methyl]-1-azabicyclo [2.2.2]octan-3-amine as a novel, nonpeptide substance P antagonist. J Med Chem 35:2591-2600.

Malmberg AB, Yaksh TL (1993) Spinal nitric oxide synthesis inhibition blocks NMDA-induced thermal hyperalgesia and produces antinociception in the formalin test in rats. Pain 54:291-300.

Mao J, Price DD, Coghill RC, Mayer DJ, Hayes RL (1992) Spatial patterns of spinal cord $\left[{ }^{14} \mathrm{C}\right]$-2-deoxyglucose metabolic activity in a rat model of painful peripheral mononeuropathy. Pain 50:89-100.

McCall WD, Tanner KD, Levine JD (1996) Formalin induces biphasic activity in C-fibers in the rat. Neurosci Lett 208:45-48.

McCarson KE, Goldstein BD (1991) Release of substance P into the superficial dorsal horn following nociceptive activation of the hindpaw of the rat. Brain Res 568:109-115.

McLean S, Ganong AH, Seeger TF, Bryce DK, Pratt KG, Reynolds LS, Siok CJ, Lowe JA, Heym J (1991) Activity and distribution of binding sites in brain of a nonpeptide substance $\mathrm{P}\left(\mathrm{NK}_{1}\right)$ receptor antagonist. Science 251:437-439.

McLean S, Ganong A, Seymour PA, Snider RM, Desai MC, Rosen T, Bryce DK, Longo KP, Reynolds LS, Robinson G, Schmidt AW, Siok C, Heym J (1993) Pharmacology of CP-99,994; a nonpeptide antagonist of the tachykinin neurokinin-1 receptor. J Pharmacol Exp Ther 267:472-479.

Mjellem-Joly N, Lund A, Berge O-G, Hole K (1992) Intrathecal coadministration of substance P and NMDA augments nociceptive responses in the formalin test. Pain 51:195-198.

Ohkubo T, Shibata M, Takahashi H, Inoki R (1990) Roles of substance $\mathrm{P}$ and somatostatin on transmission of nociceptive information induced by formalin in spinal cord. J Pharmacol Exp Ther 252:1261-1268.

Puig S, Sorkin LS (1996) Formalin-evoked activity in identified primary afferent fibers: systemic lidocaine suppresses phase- 2 activity. Pain 64:345-355.

Rossi A, Decchi B (1997) Changes in Ib heteronymous inhibition to soleus motoneurones during cutaneous and muscle nociceptive stimulation in humans. Brain Res 774:55-61.

Ruiz-Gayo M, Baamonde A, Turcaud S, Fournie-Zaluski M-C, Roques BP (1992) In vivo occupation of mouse brain opioid receptors by endogenous enkephalins: blockade of enkephalin degrading enzymes by RB 101 inhibits [ ${ }^{3} \mathrm{H}$ ]diprenorphine binding. Brain Res 571:306-312.

Rupniak NMJ, Carlson E, Boyce S, Webb JK, Hill RG (1996) Enantioselective inhibition of the formalin paw late phase by the $\mathrm{NK}_{1}$ receptor antagonist L-733,060 in gerbils. Pain 67:189-195.
Sakurada T, Katsumata K, Manome Y, Tan-No K, Sakurada S, Kisara K, Ohba M (1993a) Antinociceptive effects in the formalin and capsaicin tests after intrathecal administration of substance $\mathrm{P}$ analogues in mice. Eur J Pharmacol 242:47-52.

Sakurada T, Katsumata K, Yogo H, Tan-No K, Sakurada S, Kisara K (1993b) Antinociception induced by CP 96,345, a non-peptide NK-1 receptor antagonist, in the mouse formalin and capsaicin tests. Neurosci Lett 151:142-145.

Seeger TF, Sforzo GA, Pert CB, Pert A (1984) In vivo autoradiography: visualization of stress-induced changes in opiate receptor occupancy in the rat brain. Brain Res 305:303-312.

Sluka KA, Milton MA, Willis WD, Westlund KN (1997) Differential roles of neurokinin 1 and neurokinin 2 receptors in the development and maintenance of heat hyperalgesia induced by acute inflammation. Br J Pharmacol 120:1263-1273.

Svensson P, Graven-Nielsen T, Arendt-Nielsen L (1998) Mechanical hyperesthesia of human facial skin induced by tonic painful stimulation of jaw muscles. Pain 74:93-100.

Tao YX, Wei F, Zhao ZQ (1997) A contribution of neurokinin-1 receptor to formalin-induced c-fos expression in the rat spinal dorsal horn. Neurosci Lett 221:105-108.

Traub RJ (1996) The spinal contribution of substance P to the generation and maintenance of inflammatory hyperalgesia in the rat. Pain 67:151-161

Vaccarino AL, Marek P, Kest B, Weber E, Keana JFW, Liebeskind JC (1993) NMDA receptor antagonists, MK-801 and ACEA-1011, prevent the development of tonic pain following subcutaneous formalin. Brain Res 615:331-334.

Wagner JJ, Caudle RM, Neumaier JF, Chavkin C (1990) Stimulation of endogenous opioid release displaces mu receptor binding in rat hippocampus. Neuroscience 37:45-53.

Williams S, Evan GI, Hunt SP (1990) Changing patterns of c-fos induction in spinal neurons following thermal cutaneous stimulation in the rat. Neuroscience 36:73-81.

Yamamoto T, Yaksh TL (1991) Stereospecific effects of a nonpeptidic NK1 selective antagonist, CP-96,345: antinociception in the absence of motor dysfunction. Life Sci 49:1955-1963.

Yamamoto T, Yaksh TL (1992) Comparison of the antinociceptive effects of pre- and posttreatment with intrathecal morphine and MK801, an NMDA antagonist, on the formalin test in the rat. Anesthesiology 77:757-763.

Yamamoto T, Shimoyama N, Mizuguchi T (1993) Nitric oxide synthase inhibitor blocks spinal sensitization induced by formalin injection into the rat paw. Anesth Analg 77:886-890.

Yashpal K, Wright DM, Henry JL (1982) Substance P reduces tail-flick latency: implications for chronic pain syndromes. Pain 14:155-167.

Yashpal K, Gauthier SG, Henry JL (1985) Substance P given intrathecally at the spinal T9 level increases adrenal output of adrenaline and noradrenaline in the rat. Neuroscience 15:529-536.

Yashpal K, Radhakrishnan V, Coderre TJ, Henry JL (1993) CP-96,345, but not its stereoisomer, CP-96,344, blocks the nociceptive responses to intrathecally administered substance $\mathrm{P}$ and to noxious thermal and chemical stimuli in the rat. Neuroscience 52:1039-1047.

Yashpal K, Kar S, Quirion R, Hui-Chan CWY, Henry JL (1994) Noxious stimulation decreases substance $\mathrm{P}$ binding in rat spinal dorsal horn: competition by endogenous ligand. NeuroReport 5:2101-2104.

Yashpal K, Pitcher GM, Henry JL (1995) Noxious peripheral stimulation produces antinociception mediated via substance $\mathrm{P}$ and opioid mechanisms in the rat tail-flick test. Brain Res 674:97-103.

Yashpal K, Henry JL, Coderre TJ (1996) Prolonged decrease of substance $\mathrm{P}$ binding in rat spinal cord dorsal horn induced by noxious chemical stimulation of the hind paw with formalin. Soc Neurosci Abstr 22:872. 